\title{
Rapid release of molecular hydrogen during anaerobic weathering of basaltic glass
}

\author{
JiAN GONG ${ }^{1}$, KEVIN CANNON $^{2}$, JOEL HUROWITZ ${ }^{3}$, \\ KATHRYN M. STACK ${ }^{4}$, BENJAMIN P. WEISS ${ }^{5}$ AND TANJA \\ BOSAK $^{6}$ \\ ${ }^{1}$ gojian@mit.edu \\ 2cannon@ucf.edu \\ 3joel.hurowitz@stonybrook.edu \\ ${ }^{4}$ kathryn.m.stack@jpl.nasa.gov \\ ${ }^{5}$ bpweiss@mit.edu \\ 6tbosak@mit.edu
}

Sampling strategies for the Mars 2020 rover mission require a better understanding of water-rock interactions in basalt-derived sediments and sedimentary structures that can be produced by these interactions. Millimeter-scale early diagenetic nodules and spindle-shaped ridges associated with early diagenetic cements in the Sheepbed mudstone of the Yellowknife Bay formation in Gale crater present intriguing examples of such structures $[1,2]$. These nodules and ridges are tentatively attributed to the production of gas within sediments and subsequent lithification. We experimentally constrain conditions conducive to the abiotic generation of gases in Mars-analog sediments incubated in sterile water in equilibrium with $0.05-0.2$ bar $\mathrm{CO}_{2} / \mathrm{N}_{2}$ at $\mathrm{pH}$ 6.5-7 and $22{ }^{\circ} \mathrm{C}$. The most vigorous $\mathrm{H}_{2}$ release, $23 \mathrm{nmol}\left(\mathrm{H}_{2}\right) \mathrm{hr}^{-1} \mathrm{~g}^{-1}$ (sediment), was measured during the anaerobic weathering of basaltic glass. This process released dissolved Fe and silica and was accompanied by the formation of millimeter-sized gas bubbles. The bubbles were trapped within clay-sized sediments that were highly magnetic. Within weeks, the topography of the sediment surface roughened and exhibited linear ridge-like structures. These experiments identify the weathering of basaltic glass under a high- $\mathrm{pCO}_{2}$ atmosphere as a plausible mechanism for the production of $\mathrm{H}_{2}$ gas during sediment deposition in martian lakes. This process may have contributed to the warming of Mars' climate, formation of authigenic minerals such as magnetite [3] and the supply of $\mathrm{H}_{2}$. It may also explain the origin of magnetite-rich sediments observed at Gale and the strong magnetization of martian crust. The rapid released $\mathrm{H}_{2}$ may have served as an electron donor for any abiotic, prebiotic, and biotic redox reactions that took place during the formation of river networks and lakes on Mars.

[1] Stack, K. M. et al. (2014), JGR: Planets 119, 1637-1664. [2] Léveillé, R. J. et al. (2014), JGR: Planets 119, 2398-2415.

[3] Tosca, N. J. et al. (2018), Nature Geoscience 11, 635-639. 